\title{
Metaplastic Lesions of the Extrahepatic Bile Ducts: A Morphologic and Immunohistochemical Study
}

\author{
Mai P. Hoang, M.D., Linda A. Murakata, M.D., Alvaro L. Padilla-Rodriguez, M.D., \\ Jorge Albores-Saavedra, M.D. \\ Division of Anatomic Pathology (MPH, JA-S), The University of Texas Southwestern Medical Center, \\ Dallas, Texas; Department of Hepatic and Gastrointestinal Pathology (LAM), Armed Forces Institute of \\ Pathology, Washington, D.C.; and Pathology Unit (ALP-R), General Hospital, Mexico City, Mexico
}

\begin{abstract}
Although metaplastic changes can occur in the extrahepatic bile ducts, a detailed morphologic study of these lesions has not been done. We examined the bile duct mucosa in 42 pancreaticoduodenectomy specimens, 32 with neoplastic lesions and ten with inflammatory lesions of the extrahepatic bile ducts, to assess the prevalence and type of metaplastic lesions. For comparison, the common bile ducts from 10 autopsy cases were reviewed. Twenty of the 42 total cases (48\%), 13 of the 32 neoplastic cases $(40 \%)$, and 7 of the 10 inflammatory cases (70\%) had metaplastic changes. Pyloric gland metaplasia was the most common type (16/20 cases; 80\%), whereas intestinal metaplasia was seen in $1 / 20$ cases ( $5 \%)$. A combination of pyloric gland and intestinal metaplasia occurred in $2 / 20$ cases $(10 \%)$, and squamous metaplasia plus the abovementioned two types of metaplasia was seen in 1/20 cases $(5 \%)$. None of the normal common bile ducts obtained from ten autopsies had metaplastic changes. Endocrine cells were identified in nine (56\%) of 17 metaplastic lesions. In contrast, endocrine cells within the intramural glands were seen in only 2 of the 10 normal common bile ducts. Although a significant proportion of carcinomas (6/13 cases) was in close proximity to areas of metaplasia, we were unable to find dysplastic foci within the metaplastic glands or the metaplastic surface epithelium. Reactive atypical cells involved the surface biliary epithelium and intramural glands and were associated with inflammation and metaplastic changes. The presence of goblet, mucinous, squamous, and reactive atypical cells in association with hyperplasia of intramural glands in frozen sections
\end{abstract}

Copyright (C) 2001 by The United States and Canadian Academy of Pathology, Inc.

VOL. 14, NO. 11, P. 1119, 2001 Printed in the U.S.A.

Date of acceptance: June 27, 2001.

Address reprint requests to: Jorge Albores-Saavedra, M.D., Department of Pathology, The University of Texas Southwestern Medical Center, 5323 Harry Hines Blvd., Dallas, TX 75235; e-mail: jorge.albores@utsouthwestern.edu; fax: 214-590-1411. or small biopsy specimens may be mistaken for malignancy; hence, recognition of these lesions is of diagnostic importance.

KEY WORDS: Extrahepatic bile duct, Intestinal metaplasia, Metaplasia, Pyloric gland metaplasia, Squamous metaplasia.

Mod Pathol 2001;14(11):1119-1125

Intestinal and pyloric metaplasia are common metaplastic changes in chronic cholecystitis and cholelithiasis $(1,2)$. Similar changes may occur in association with inflammation and neoplasms of the extrahepatic bile ducts, but detailed morphologic and immunohistochemical studies of these lesions have not been done. Although metaplastic changes of the extrahepatic bile ducts have been described adjacent to areas of dysplasia and carcinoma, very little information is available on the subject (3). In fact, we were unable to find a single publication on metaplastic lesions of the extrahepatic bile ducts in the American medical literature. Reactive surface biliary cells and metaplastic cells often coexist in inflammatory lesions of the extrahepatic bile ducts. Their recognition in bile duct brushings, frozen sections, or small biopsy specimens may be problematic, and a diagnosis of malignancy can be rendered erroneously.

In this study, we examined the nonneoplastic bile duct mucosa of forty-two pancreaticoduodenectomy specimens with either neoplastic or inflammatory processes of the extrahepatic bile ducts to assess the prevalence and type of metaplastic lesions. For comparison, the proximal, middle, and distal portions of the common bile duct from 10 autopsy cases were also reviewed.

\section{MATERIALS AND METHODS}

The consultation file of one of the authors (J.A.S.) and the surgical pathology files of the University of Texas Southwestern Medical Center, Dallas, Texas, 
and the Armed Forces Institute of Pathology, Washington, D.C., were searched for pancreaticoduodenectomy specimens with inflammatory as well as neoplastic lesions of the extrahepatic bile ducts. Forty-two cases containing normal-appearing bile duct mucosa adjacent to either tumors or chronic inflammation formed the basis of this study. Sections of the common bile duct margin and representative sections of the common bile duct, proximal and distal from the lesion, were examined. The number of sections of the common bile duct ranged from 3 to 10, with an average of 6 . In ten cases, the bile duct showed only a nonspecific inflammatory process, whereas in the remaining 32 cases, it harbored either a benign or a malignant tumor. However, inflammatory changes in the wall of the bile ducts were also noted in four of the cases harboring neoplasms.

The clinical history was obtained from the patients' charts or from letters from the referring pathologists. In four cases, surgical stents were placed for more than a two-week duration.

In addition, sections from the proximal, middle, and distal portions of the common bile duct from 10 autopsy cases performed at the General Hospital of Mexico City, Mexico, were used as controls. All 10 patients were adults who died with no evidence of biliary tract disease.
Four-micrometer-thick sections were cut from the paraffin blocks and stained with hematoxylin and eosin. Additional paraffin sections of selected available blocks were obtained for immunohistochemical studies, which were performed on an automated immunostainer (Biotek System, Ventana, Tucson, AZ) using the standard avidin-biotin peroxidase complex technique, the heat-induced epitope retrieval buffer, and primary antibody against chromogranin (clone: DAK-A3; dilution 1:700; DAKO, Carpinteria, CA).

\section{RESULTS}

Twenty of the 42 cases (48\%) had metaplastic changes involving the extrahepatic bile ducts. The salient clinicopathologic features of these 20 patients are presented in Table 1 . The male to female ratio was 3:2, with patient ages ranging from 26 to 84 years (median, 63 years; mean, 61 years). Pyloric gland metaplasia alone was seen in sixteen cases, intestinal metaplasia in one case, both pyloric and intestinal metaplasia in two cases, and squamous metaplasia plus pyloric and intestinal metaplasia in one case.

The remaining twenty-two cases did not show metaplastic lesions in the extrahepatic bile ducts.

TABLE 1. Clinical and Pathologic Features of 20 Patients with Metaplastic Lesions of the Extrahepatic Bile Ducts

\begin{tabular}{|c|c|c|c|c|}
\hline Case & Age (y)/Sex & Types of Metaplasia & $\begin{array}{l}\text { Presence of } \\
\text { Neuroendocrine Cells }\end{array}$ & Pathology Diagnosis \\
\hline 1 & $32 / \mathrm{F}$ & Pyloric & + & Papillary and invasive adenocarcinoma of the common bile duct \\
\hline 2 & $72 / \mathrm{M}$ & Pyloric & + & $\begin{array}{l}\text { Papillary and invasive adenocarcinoma of ampullary portion of the } \\
\text { common bile duct }\end{array}$ \\
\hline 3 & $42 / \mathrm{F}$ & Pyloric & + & Papillary adenocarcinoma of left hepatic duct \\
\hline 4 & $52 / \mathrm{M}$ & Pyloric & - & $\begin{array}{l}\text { Adenocarcinoma of ampullary portion of the common bile duct } \\
\text { and head of pancreas }\end{array}$ \\
\hline 5 & $75 / F$ & Pyloric & - & $\begin{array}{l}\text { Invasive adenocarcinoma arising from tubulovillous adenoma of } \\
\text { distal common bile duct and ampulla of Vater }\end{array}$ \\
\hline 6 & $72 / \mathrm{M}$ & Pyloric & - & Papillary adenocarcinoma of the common bile duct \\
\hline 7 & $74 / \mathrm{F}$ & Pyloric & - & Adenosquamous carcinoma of the common bile duct \\
\hline 8 & $63 / \mathrm{M}$ & Pyloric & + & Adenocarcinoma of distal common bile duct and ampulla of Vater \\
\hline 9 & $70 / \mathrm{M}$ & Pyloric & - & $\begin{array}{l}\text { Tubulovillous adenoma arising from distal common bile duct and } \\
\text { ampulla of Vater }\end{array}$ \\
\hline 10 & $60 / \mathrm{M}$ & Pyloric & + & Common bile duct adenoma \\
\hline 11 & $58 / \mathrm{M}$ & Pyloric & ND & $\begin{array}{l}\text { Adenomyomatous hyperplasia of ampulla of Vater and accessory } \\
\text { pancreatic duct }\end{array}$ \\
\hline 12 & $48 / \mathrm{M}$ & Pyloric & + & $\begin{array}{l}\text { Chronic fibrosing pancreatitis and chronic inflammation in } \\
\text { common bile duct wall }\end{array}$ \\
\hline 13 & $78 / \mathrm{M}$ & Pyloric & - & Stones in the common bile duct \\
\hline 14 & $81 / \mathrm{M}$ & Pyloric & ND & Focal severe reactive atypia of common bile duct \\
\hline 15 & $73 / \mathrm{M}$ & Pyloric & ND & Extensive mucosal ulceration and chronic inflammation \\
\hline 16 & $57 / \mathrm{F}$ & Pyloric & - & $\begin{array}{l}\text { Invasive adenocarcinoma of the ampullary portion of the common } \\
\text { bile duct }\end{array}$ \\
\hline 17 & $53 / \mathrm{M}$ & Intestinal & + & $\begin{array}{l}\text { Invasive adenocarcinoma of mid portion of the common hepatic } \\
\text { duct }\end{array}$ \\
\hline 18 & $84 / F$ & $\begin{array}{l}\text { Pyloric } \\
\text { intestinal }\end{array}$ & - & Adenocarcinoma arising from the common bile duct \\
\hline 19 & $37 / \mathrm{F}$ & $\begin{array}{l}\text { Pyloric } \\
\text { intestinal }\end{array}$ & + & Fibrosis and chronic inflammation of the common bile duct \\
\hline 20 & $26 / F$ & $\begin{array}{l}\text { Pyloric } \\
\text { intestinal } \\
\text { squamous }\end{array}$ & + & Inflammatory stricture of the common bile duct \\
\hline
\end{tabular}

ND, not done. 


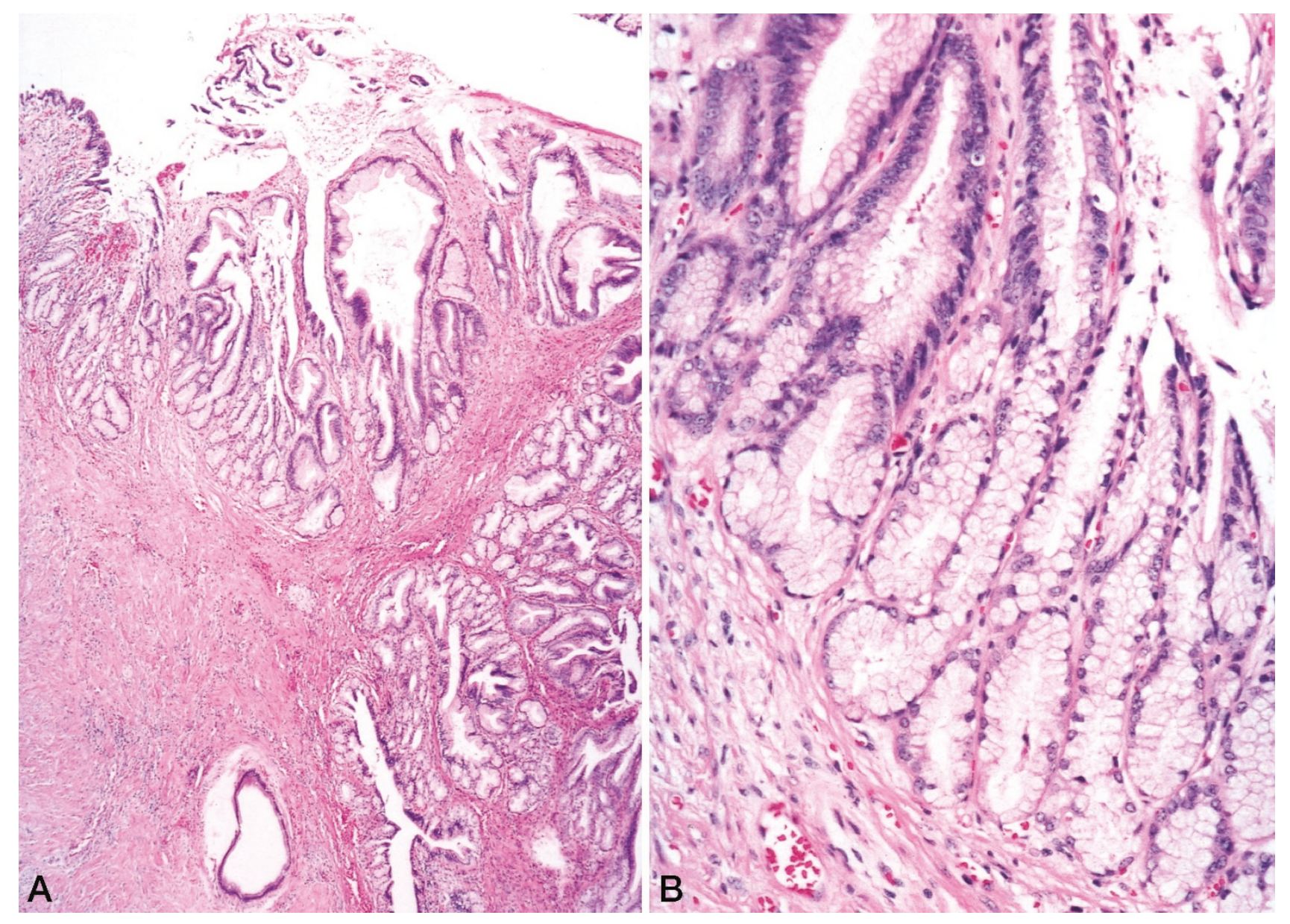

FIGURE 1. A, most of the surface epithelium is ulcerated. Lobules of metaplastic glands resembling pyloric glands are seen in the lamina propria. Some of the glands are cystically dilated. B, the superficial biliary epithelium shows reactive atypia. The glands resemble pyloric glands.

The male to female ratio of these patients was $7: 4$, with their ages ranging from 34 to 86 years (median, 67 years; mean, 64 years). Four cases had a nonneoplastic diagnosis, and the remaining 18 cases were associated with carcinomas.

The common bile duct was examined in ten autopsy cases of patients with no evidence of biliary disease. The ages of these patients ranged from 19 to 84 years (median, 49 years; mean, 45 years). None of these ten cases had metaplastic changes. There was an average of two small lobules of intramural glands per cross-section. Two cases $(20 \%)$ had rare neuroendocrine cells identified within the intramural glands by chromogranin immunostain.

The metaplastic change was focal in both the inflammatory lesions and in the tumors. Seven of the 20 metaplastic cases arose in a background of chronic inflammation, whereas the remaining thirteen cases were associated with a neoplastic process-adenoma in two cases, adenocarcinoma in ten cases, and adenosquamous carcinoma in one case. The carcinomas arose in the common bile duct in nine cases, including five that arose in the ampullary portion of the common bile duct. Two carcinomas arose in the hepatic duct.
Hyperplasia of the intramural glands of the common bile ducts was seen in 17 of the 20 cases with metaplastic lesions. These glands arose from invagination of the surface epithelium. They were greater

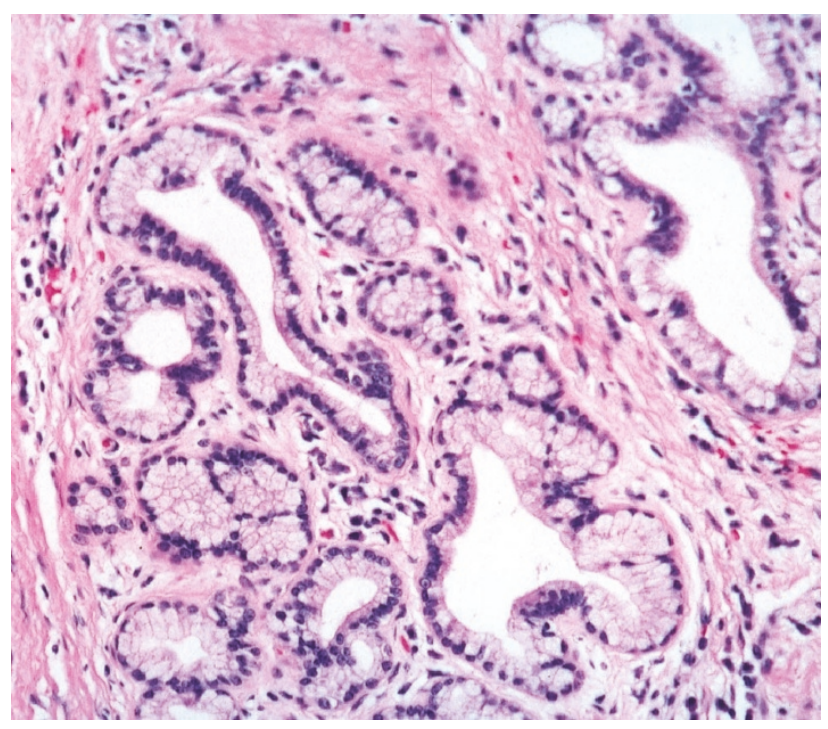

FIGURE 2. Metaplastic pyloric type epithelium has replaced part of the normal biliary epithelium of these intramural glands. 
in number and were arranged in larger lobules than those seen in the control autopsy cases. The glands were often confined to the lamina propria, although occasionally they extended into the muscular layer and adventitia.

In the sixteen cases with pyloric gland metaplasia, the changes involved the surface epithelium, epithelial invaginations (sacculi of Beale), and intramural glands in variable proportions (Fig. 1). In 13 cases, hyperplasia of the intramural glands was noted. The surface epithelium and the epithelial invaginations were lined by tall columnar mucincontaining cells resembling gastric foveolar epithelium. The metaplastic intramural glands maintained their lobular architecture. They were lined by mucin-containing columnar cells with basally located nuclei, which were often compressed against the basement membrane. In some areas, transition from normal biliary epithelium to mucinous metaplastic epithelium was seen within the same gland (Fig. 2). Paneth cells with numerous fine cytoplasmic eosinophilic granules were seen admixed with the mucin-containing cells in three cases (Fig. 3). Few cells contained both mucin and Paneth granules. In eight of these sixteen cases (50\%), endocrine cells located above the basement membrane were found between the mucincontaining cells (Fig. 4).

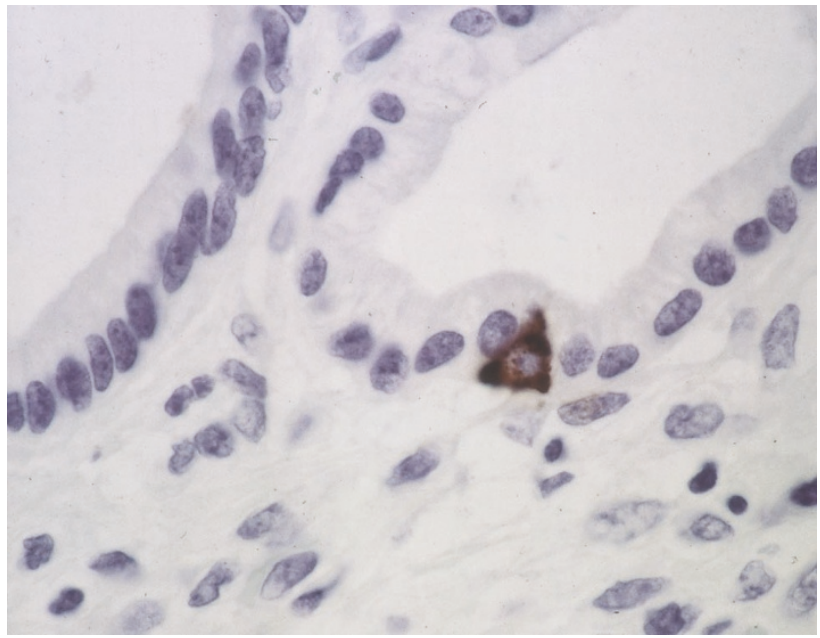

FIGURE 4. A single endocrine cell is seen between cuboidal and columnar mucinous cells.

In four cases with intestinal metaplasia, either alone or in combination with other types of metaplasia, gland-like structures containing variable numbers of goblet cells, columnar cells with a brush border, Paneth cells, and endocrine cells were seen, with goblet cells being the predominant type (Fig. 5). Only at high magnification could one appreciate the fine Paneth granules in some of the

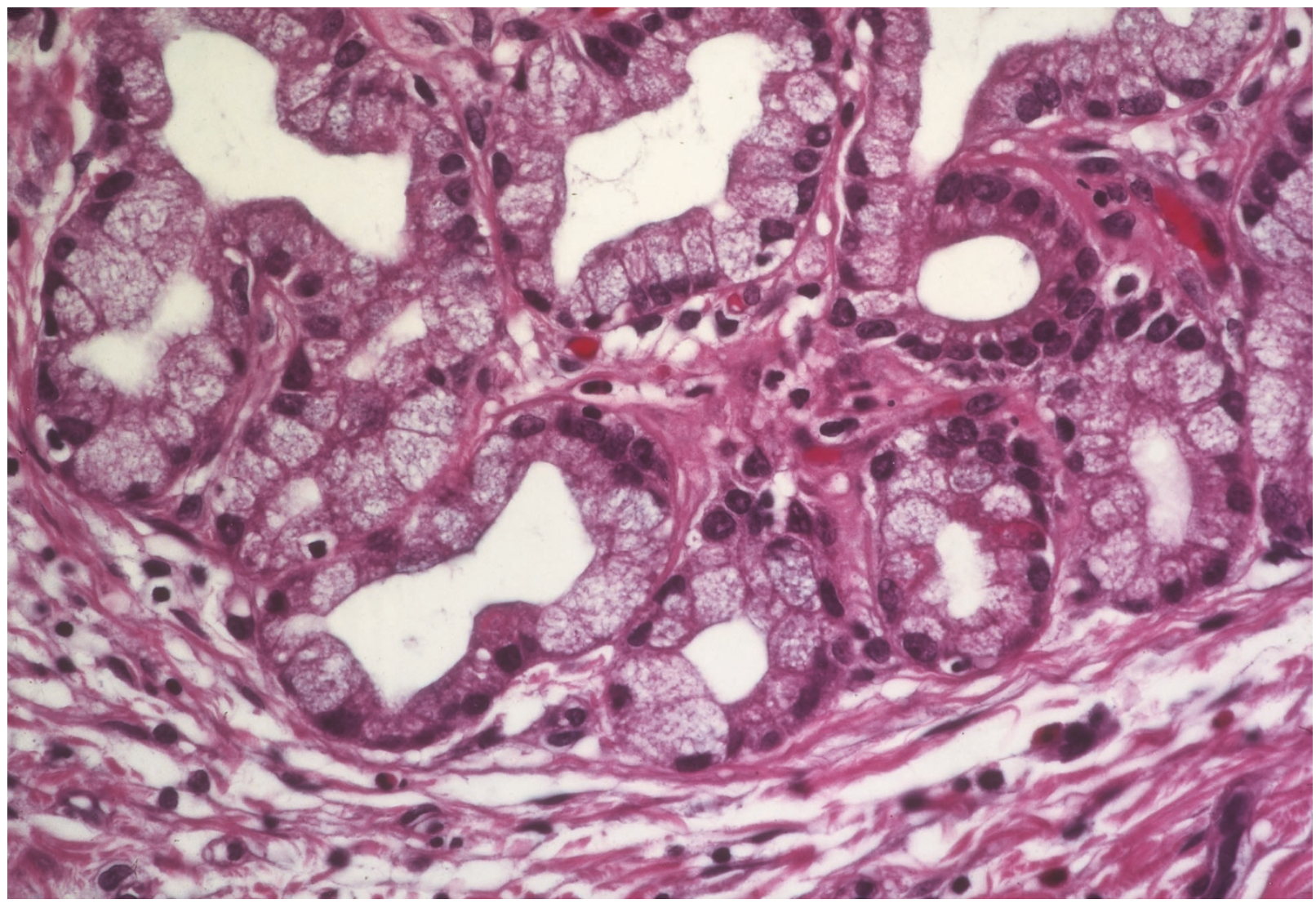

FIGURE 3. The pyloric metaplastic glands are lined by tall columnar cells with basally located nuclei. Some cells contain Paneth granules. 


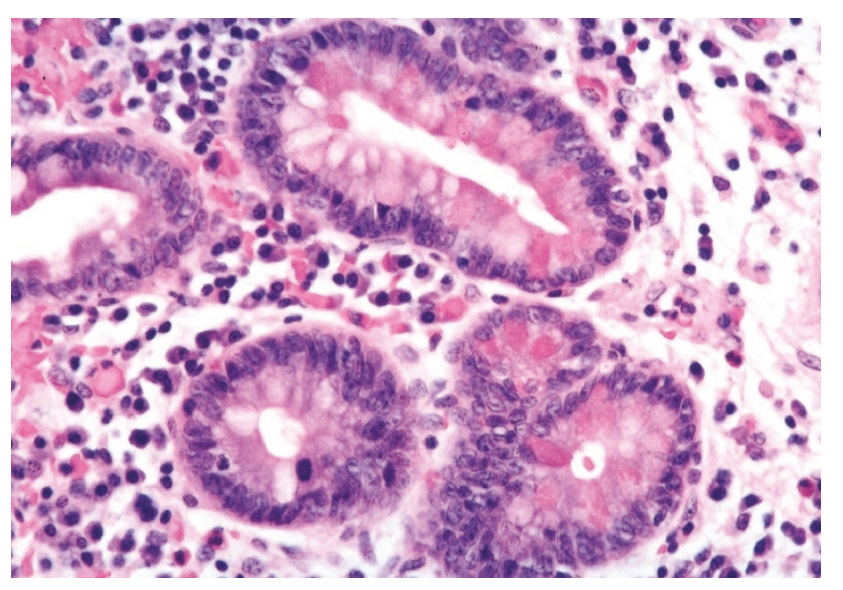

FIGURE 5. Intestinal metaplasia. The glands contain goblet cells, and Paneth granules are seen in some cells.

cells. Demonstrated by chromogranin immunostain in three cases, endocrine cells that rested above the basal lamina were seen intermixed with the columnar and goblet cells. These endocrine cells were also present in the normal intramural glands.

In a single case, the surface columnar biliary epithelium was replaced by stratified mature squamous epithelium (Fig. 6). In addition, invaginations of the surface biliary epithelium were seen adjacent to lobules of metaplastic glands. These glands were lined by columnar cells, some with foamy cytoplasm, as well as goblet and Paneth cells. Again, chromogranin highlighted the presence of endocrine cells.

Reactive atypia of the surface epithelium was also a constant feature. The most severe reactive changes were seen in the four cases in which the surgical stents were placed. It occurred more often in the surface epithelium than in the intramural glands. Reactive atypia was characterized by a heterogeneous cell population. Cuboidal and colum-

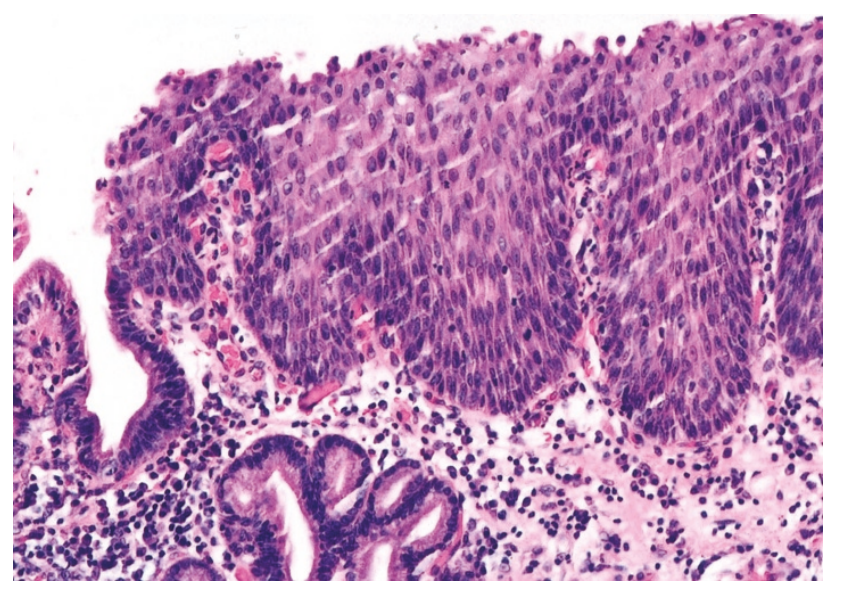

FIGURE 6. Mature metaplastic squamous epithelium has replaced the surface columnar biliary epithelium of the common bile duct.

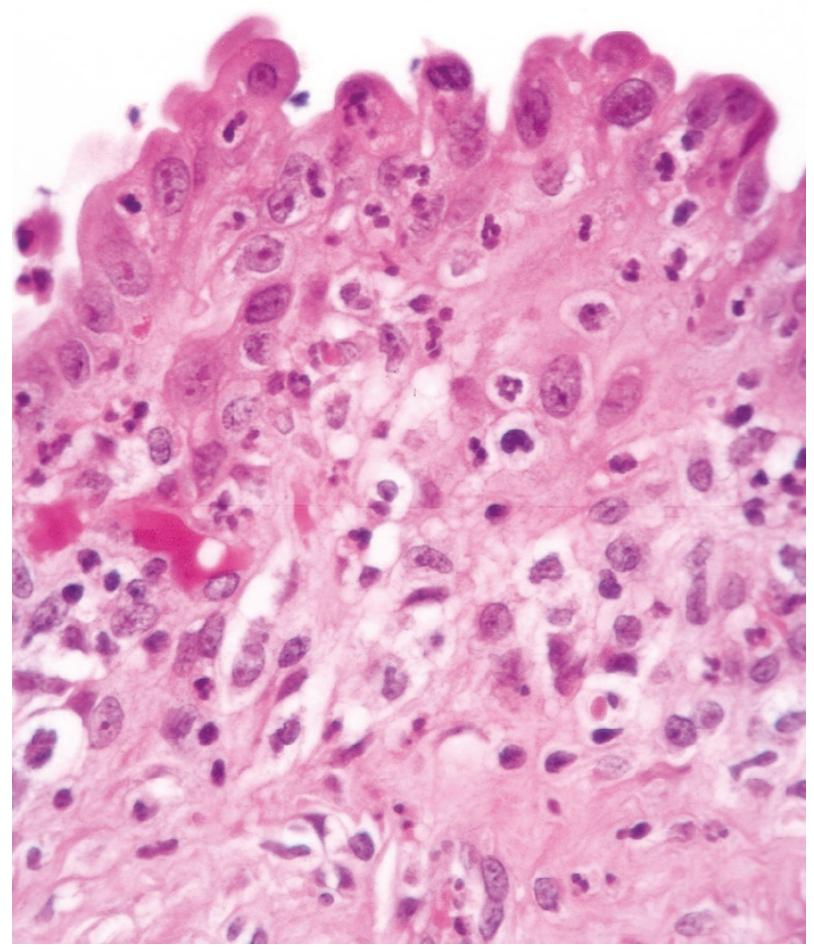

FIGURE 7. Reactive atypia of the surface biliary epithelium with intraepithelial and subepithelial neutrophils.

nar cells with basophilic, clear, or lightly eosinophilic cytoplasm predominated. The nuclei were vesicular or hyperchromatic and contained prominent nucleoli. Mitotic figures were common. Intraepithelial and subepithelial inflammatory cells, consisting predominantly of neutrophils, were nearly always present (Fig. 7). These atypical reactive cells often lead to diagnostic problems, especially in interpreting the common bile duct margin frozen sections in five of our cases. In fact, in one case of foveolar and pyloric gland metaplasia and in another case in which squamous metaplasia was seen as well, the diagnosis of carcinoma was seriously considered in the bile duct brushings because

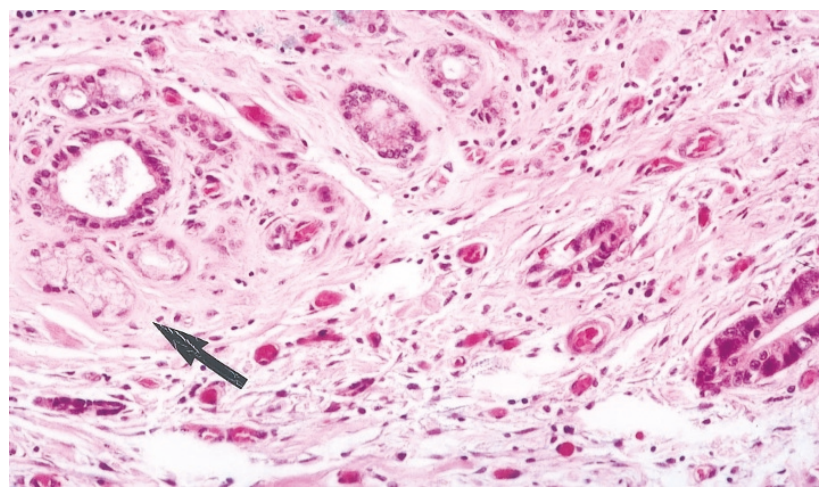

FIGURE 8. Neoplastic glands are present adjacent to the metaplastic glands (arrow). 
of the presence of reactive atypical cells. Although carcinomas were seen in close proximity to foci of metaplasia, no dysplastic foci were found in the metaplastic glands or within the surface gastric foveolar epithelium (Fig. 8).

\section{DISCUSSION}

We have shown that metaplastic lesions occur in association with inflammatory lesions, as well as in association with benign and malignant tumors of the extrahepatic bile ducts. In our series, metaplastic lesions accounted for $48 \%$ of all our cases, having been identified in $70 \%$ of the inflammatory cases and in $40 \%$ of the neoplastic cases. The metaplastic lesions include pyloric gland metaplasia, gastric foveolar metaplasia, intestinal metaplasia, and squamous metaplasia. Pyloric gland metaplasia was the most common form. Gastric metaplasia, as defined by the presence of parietal cells, chief cells, and mucous neck cells, was not identified. In all cases, the metaplastic pyloric glands involved the intramural glands, which maintained their normal lobular architecture.

In a previous study, Laitio reported a high incidence $(80 \%)$ of metaplastic changes within the nonmalignant mucosa adjacent to either dysplasia or carcinoma of the extrahepatic bile ducts (3). However, reactive atypia, which is difficult to distinguish from and is often confused with dysplasia, was not mentioned in this study. Pyloric gland metaplasia involving the intramural glands was the most common form of metaplasia in our series, whereas gastric foveolar metaplasia, usually confined to the surface epithelium was less frequent. Intestinal metaplasia was often associated with pyloric gland metaplasia, suggesting a common cell precursor (2). Squamous metaplasia has not been described in the extrahepatic bile ducts, and our case appears to be the first reported so far. This case was unique in that it also had pyloric as well as intestinal metaplasia.

In $75 \%$ of all cases with metaplastic lesions, a significant degree of chronic inflammation was noted. It is possible that chronic inflammation might have induced the appearance of multipotential stem cells with subsequent differentiation into various intestinal phenotypes. The presence of cells containing both cytoplasmic mucin and Paneth granules, the presence of neuroendocrine cells, and a combination of several types of metaplastic changes within the same lesion lend support to our hypothesis. In addition, an ultrastructural study of metaplastic lesions in the gallbladder has demonstrated transitions between normal columnar cells and those with well-developed intestinal-type villi (4).
It has been hypothesized that mechanical irritation by gallstones and chronic inflammation give rise to regeneration of the mucosa and mucosal intestinal metaplasia, thus creating an environment suitable for oncogenesis in the gallbladder (2). Moreover, dysplasia and carcinoma of the extrahepatic bile ducts have been described in association with ulcerative colitis and primary sclerosing cholangitis, both of which conditions may lead to metaplastic changes (5-7). Intestinal metaplasia rather than pyloric gland metaplasia has been suspected to play a premalignant role in both the gallbladder and the extrahepatic bile ducts (8). In an experimental study involving 20 minipigs, an anastomosis was constructed between an isolated pancreas-duodenal segment and the gallbladder (9). Intestinal metaplasia of the common bile duct and gallbladder was seen in $20 \%$ of the cases, and the severity of the epithelial changes was proportional to the duration of the experiment (9). In humans, an increased incidence of carcinoma has been shown in patients with an anomalous choledochopancreatic junction that is associated with intestinal metaplasia (10). In this study, however, we were unable to find foci of dysplasia in the metaplastic areas; therefore, the possibility that the tumor induced the metaplastic changes cannot be excluded.

Previous studies have suggested that invasive carcinomas of the extrahepatic bile ducts evolve through the dysplasia-carcinoma sequence $(1,3$, 10, 11). Laitio (3) and Davis et al. (11) noted dysplastic changes in the adjacent biliary epithelium in $45 \%$ and $30 \%$ of their extrahepatic bile duct carcinomas, respectively. In our prior study of 61 carcinomas of the extrahepatic bile ducts, we found dysplasia and carcinoma in situ in 6 cases (10\%) (1). In contrast, Suzuki et al. (8) found high-grade dysplasia in $75 \%$ and carcinoma in situ) in $42 \%$ of invasive carcinomas. These higher percentages were likely the result of the detailed computerassisted three-dimensional reconstruction of the biliary tree employed in the latter study. In addition, our prior study was comprised of large tumors, which probably had obliterated the adjacent dysplastic changes.

The existence of endocrine cells in areas of intestinal metaplasia of the extrahepatic bile ducts has been established by means of silver stain (3). Although Laitio reported its presence in only one of 12 cases with metaplastic changes, endocrine cells were identified in nine of our 16 cases (56\%) (3). This discrepancy can be attributed to the sensitive detection of endocrine cells by immunohistochemistry. As previously described (12), rare endocrine cells were found within the intramural glands of the normal common bile duct. Carcinoid tumors of the extrahepatic bile ducts, which characteristically 
show a submucosal location, may arise from these endocrine cells (13). Approximately one third of well- to moderately differentiated adenocarcinomas of the extrahepatic bile ducts contained endocrine cells that were immunoreactive for the general endocrine markers (14). Their clinical significance however is unknown.

The differential diagnosis of pyloric gland metaplasia includes a well-differentiated adenocarcinoma, gastric foveolar type, of the extrahepatic bile ducts (15). Although this neoplasm has bland nuclear features and a lobular pattern, it would present as a polypoid mass. Moreover, the deep portion of the tumor shows cytologic atypia and commonly exhibits perineural invasion. Gastric foveolar and pyloric gland metaplasia are microscopic findings confined to the surface epithelium and intramural glands, respectively; the glands maintain a well-defined lobular architecture, and do not lead to the formation of a mass.

Because there are no specific histochemical or immunohistochemical markers for identification of pyloric glands and gastric foveolar epithelium, the diagnosis of metaplastic lesions of the extrahepatic bile ducts is based solely upon histologic features. Recognition of the metaplastic lesions of the extrahepatic bile ducts is important, especially in bile duct brushings, frozen sections, or small biopsy specimens. Reactive surface biliary cells as well as goblet, mucinous, or squamous cells in these specimens can be misinterpreted, and a diagnosis of malignancy can be rendered erroneously.

\section{REFERENCES}

1. Albores-Saavedra J, Henson DE, Klimstra DS. Tumors of the gallbladder, extrahepatic bile ducts and ampulla of Vater. Fascicle 27. Washington, DC: Armed Forces Institute of Pathology; 2000.

2. Albores-Saavedra J, Nadji M, Henson DE, Ziegels-Weissman J, Mones JM. Intestinal metaplasia of the gallbladder: a mor- phologic and immunohistochemical study. Hum Pathol 1986;17:614-20.

3. Laitio M. Carcinoma of extrahepatic bile ducts: a histopathologic study. Pathol Res Pract 1983;178:67-72.

4. Laitio M, Nevalainen TJ. An electron microscopic study of intestinal metaplasia in human gallbladder. Beitr Pathol 1975;155:297-308.

5. Haworth AC, Manley PN, Groll A, Pace R. Bile duct carcinoma and biliary tract dysplasia in chronic ulcerative colitis. Arch Pathol Lab Med 1989;113:434-6.

6. Ludwig J, Wahlstrom HE, Batts KP, Wiesner RH. Papillary bile duct dysplasia in primary sclerosing cholangitis. Gastroenterology 1992;102:2134-8.

7. Wee A, Ludwig J, Coffey RJ Jr, LaRusso NF, Wiesner RH. Hepatobiliary carcinoma associated with primary sclerosing cholangitis and chronic ulcerative colitis. Hum Pathol 1985; 16:719-26.

8. Suzuki M, Takahashi T, Ouchi K, Matsuno S. The development and extension of hepatohilar bile duct carcinoma. A three-dimensional tumor mapping in the intrahepatic biliary tree visualized with the aid of a graphics computer system. Cancer 1989;64:658-66.

9. Benhidjeb T, Said S, Rudolph B, Siegmund E. Anomalous pancreatico-biliary junction-report of a new experimental model and review of the literature. J Pediatr Surg 1996;31: 1670-4.

10. Sameshima Y, Uchimura M, Muto Y, Maeda J, Tsuchiyama $\mathrm{H}$. Coexistent carcinoma in congenital dilatation of the bile duct and anomalous arrangement of the pancreatico-bile duct. Cancer 1987;60:183-189.

11. Davis RI, Sloan JM, Hood JM, Maxwell P. Carcinoma of the extrahepatic biliary tract: a clinicopathological and immunohistochemical study. Histopathology 1988;12:623-31.

12. Dancygier H, Klein U, Leuschner U, Hubner K, Classen M. Somatostatin-containing cells in the extrahepatic biliary tract of humans. Gastroenterology 1984;86:892-6.

13. Maitra A, Krueger JE, Tascilar M, Offerhaus GHA, AngelesAngeles A, Klimstra DS, Hrubran RH, Albores-Saavedra J. Carcinoid tumors of the extrahepatic bile ducts: a study of seven cases. Am J Surg Pathol 2000;24:1501-10.

14. Yamamoto M, Takahashi I, Iwamoto T, Mandai K, Eiichi T. Endocrine cells in extrahepatic bile duct carcinoma. J Cancer Res Clin Oncol 1984;108:331-5.

15. Albores-Saavedra J, Delgado R, Henson DE. Welldifferentiated adenocarcinoma, gastric foveolar type, of the extrahepatic bile ducts: a previously unrecognized and distinctive morphologic variant of bile duct carcinoma. Ann Diagn Pathol 1999;3:75-80. 